PRESENTATION OF THE DOSSIER

\title{
EDUCATION MEDIATED BY TECHNOLOGY: LEARNING, INNOVATION AND PROSPECTS
}

With the overwhelming speed of technological advances and social events, Education in postmodernity is defined as a transcendent social fator and protagonist at a time in the history of humanity in which we struggle to achieve fundamental changes in the evolutionary processes of society from understanding and explaining a reality with different complex processes, of which, until recently, only scientists were in charge of investigating to understand its logic or rationality.

We, educators, have had to find new ways of interaction so the learning process can take advantage of the vast power of computers, videos, information and communication technologies (ICTs), and teleinformatics, in order to improve the educational act.

Currently, educational virtualization is not only a reality, it is also a necessity, and an alternative for the social and economic development of nations, in which online, digital, or virtual distance education, and training allow students, teachers, facilitators and administrators to attend an educational meeting, where students' autonomy is fostered through the independent search for knowledge, as well as, they develop their skills for collaborative work in virtual spaces. ${ }^{1}$

The dynamic evolution of information technology, the telecommunications, the electronic networks, and the technologies, represent a nucleus of knowledge for debate for Ibero-American academics and researchers, as well as for the rest of the world, due to its impact in the formal and non-formal education, in the generation of new strategies for teaching-learning, in the transformation of educational models, in the contributions of emerging technologies in the educational process, among multiple possibilities for analysis.

${ }^{1}$ Edel, R. (2007). La virtualización de los procesos educativos: más allá de las TIC. Reflexiones de profesionales de la educación. Metas educativa 2021. La educación que queremos para la educación de los bicentenarios. Organización de estados iberoamericanos. 
As a starting point for the discussion, we can argue that technology has several challenges to be fulfilled in Education; however, its scope will not be possible without understanding that the formula is not located in the change, but in the evolution, in the ways of conceiving, planning, implementing and evaluating educational actions in the social context.

It will not be enough to have sophisticated and modern technological resources, the experience of using technological platforms in education at all levels, the scope of distance education implemented by different Ibero-American public and private higher education institutions, neither the underutilization of software, hardware and digital resources in schools; on the contrary, it is necessary to create strategies, methods or models that underlie the meaning and the way of facing innovative education.

In the knowledge society, it is necessary to train users and consumers of technology; the fact that an educational institution has a computer center does not mean that it is used, or at least, that it is used often enough to be considered profitable. It seems that Ibero-American education has not yet responded to the expectations generated.

Given the need to train people to be capable of using technology, policies, plans, authorities, and school institutions have only responded with literacy in computer science, a condition analogous to the task of teachers regarding technology, which refers to not only know the uses or application routines, but in the contrary, to know its incorporation into the process of teaching-learning-evaluation that requires a contemplation of the process in a different way, and to measure the extent to which it will affect all the elements that compose it.

It is worth mentioning the concern to listen to the academic discourse that the research on the ICTs, as it is usually mentioned, should be the purpose of the investigation and educational discussion. However, it should be recognized that the study of ICT represents only a line of research or focus of interest on virtual learning environments (VLE), and that zoom in the perspective of the area of knowledge in question will lead us to enrich the discussion about virtualization in the educational process, which requires deepening the nature of emerging learning environments and their impact on educational processes; and, therefore, recognize them as an object of relevant study and discussion in the Ibero-American countries.

The present issue of Education Mediated by Technology: Learning, Innovation and Prospects, in congruence with the aforementioned research and discussion, includes 
25 articles that explain the teaching and learning process in different levels of academic formation, and in different Ibero-American sociocultural contexts, which contribute to the State of the $\mathrm{Art}^{2}$ of virtual learning environments (VLE), and in particular, as a collection of eight fields of knowledge associated with;

1) Policies for instrumentation and equipment of ICTs in educational spaces. Perspectives on the quality, evaluation and accreditation of ICT-mediated education, implementation and development of educational technology, teleinformatics, educational software, simulators and virtual laboratories, the cost-benefit of using digital resources in education, and the evaluation of government plans and programs for the incorporation of ICT in the educational act.

2) Analysis on the use of ICTs in the educational process. The contribution of electronic and digital media (e-mail, chat, forum, video link, video, sound and digital image, among others) in the educational practices of a networked society mediated by technology. Educational innovation in differentiated and emerging learning environments, mobile learning (smartphones and tablets), homeschooling and the field of knowledge of legislation and/or legality associated with virtual learning environments.

3) The contribution of virtual learning spaces and resources. The impact of technology platforms on education, web X.O (blogs, wikis, podcasts, e-books, web pages, etc.), virtual classrooms in schools, universities and companies, as well as the influence of scientific networks and social medias in education, the educational scope of learning objects, augmented reality and digital simulation tools.

4) Analysis of the influence of internet use in educational processes. Theoretical and empirical basis on the educational use of the Internet, the impact of digital exclusion, management and regulation of distance education, as well as research on the use of ICTs and VLEs for social inclusion and support to vulnerable groups.

5) Levels, models and modes of education mediated by technology. Systematic explanations on the educational modalities of semi-presence, e-learning,

${ }^{2}$ Edel, R. Y Navarro, y. (2015). Entornos virtuales de aprendizaje 2002-2011. Colección estados del conocimiento. Edited by anuies-comie. Isbn anuies 978-607-451-107-9, ISBN comie 978-607-792-322-0. 
mixed and mobile learning (e-b-m-net-learning), open education, lifelong education, the dynamics of virtual and open universities, as well as their constructs associated with equity, elevance, quality, coverage, inclusion and social contribution.

6) The phenomenon of educational virtualization. The transference of presence to virtuality, and connectivism to learning. The influence of cognitive processes and their possible contribution to educational transformation.

7) The open educational movement. Description. Formal knowledge about open educational resources, learning objects, repositories, remote and virtual laboratories, open-access culture and the massive open online courses (MOOC), as well as copyright, licensing and sustainability of the open resource.

8) Citizenship and digital skills. Formal approach to digital competences (eskills), knowing that it concerns the contribution of ICTs in initial teacher training, digital citizenship, literacy and digital exclusion, media management, and social behavior on the internet (Facebook, Twitter, LinkedIn, WhatsApp, Instagram, Flickr, among others).

The last lines of the Presentation of the Dossier express a sincere thanks to the group of authors who allowed the work to be carried out, to share experiences, reflections and discussions, demonstrating their great academic and professional value, which will surely contribute in an innovative way to the field of knowledge on Technology-Mediated Learning.

Finally, to extend the gratitude to the Revista Iberoamericana de Estudios en Educación (Ibero-American Journal of Studies in Education), for its invaluable editorial space and the diffusion of this thematic issue.

Dr. Rubén Edel-Navarro

Dossier Coordinator

Veracruz University

Mexico 